\title{
Communicating across cultures in South African law courts: Towards an information technology solution*
}

\author{
Russell H. Kaschula and André Mostert \\ School of Languages, P.O. Box 94, Rhodes University, Grahamstown, 6140 \\ r.kaschula@ru.ac.za and andre.mostert@ru.ac.za \\ Monwabisi K Ralarala \\ Department of African Languages, University of Stellenbosch, Private Bag X1, Matieland, 7602, \\ monwabisir@crlcommission.org.za
}

\section{Introduction}

Language rights in South Africa are entrenched in the Constitution of South Africa (Chapter 1, Section 6, Constitution of the Republic of South Africa, 1996). However, the concomitant infrastructure and organisational realities make this policy difficult to implement, especially in law courts (Kaschula and Ralarala 2004). Creating effective communicative environments has historically been constrained by lack of effective training of legal practitioners and by the lack of capacity for building translation structures. With the advancement of technology, potential solutions are becoming more apparent and it is incumbent upon the academic community to embark on a rigorous investigation into possible solutions and how these Information Communication Technology (ICT) solutions could be applied to the execution of justice in South African law courts. This article aims to open the discourse of possible solutions, via assessments of computer based translation solutions, ICT context simulations and other potential opportunities. The authors hope to initiate the interest of other language 
and legal practitioners to explore how the new technological capabilities could be harnessed to support the entrenchment of language rights in our law courts.

There are a number of approaches which can be applied to language-related aspects of intercultural communication. These include the contrastive approach, the interlanguage approach, the interactive-intercultural approach, pragmatic theories of intercultural communication, as well as sociolinguistic theories of intercultural communication (TingToomey 1999; Gudykunst and Lee 2003). It is the latter approach, the study of language in relation to society, which is used as a point of departure in this article (Trudgill 1983: 15-33). Subsumed under this sociolinguistic approach is the ethnography of speaking, containing references to observations made in the court room, as well as interviews with respected judges.

Saville-Troike (1982: 2-3) supports this approach, saying that the ethnography of communication takes language first and foremost as a socially cultural form. This is also discussed extensively in Kiesling and Paulston (2005: 1-104). In this work scholars such as Hymes and Gumperz discuss models of the interaction of language and social life. To ignore social and cultural aspects of language would be reducing it and denying any possibility of how language lives "...in the minds and on the tongues of its users" (Ting-Toomey 1999: 5).

In identifying the need for effective intercultural communication, Ting-Toomey (1999: 5) states that, "[i]n order to communicate effectively with dissimilar others, every global citizen needs to learn the fundamental concepts and skills of mindful intercultural communication." The term "mindful", in essence, requires that one concentrates on the process of communication rather than the outcome thereof. "In order to communicate effectively in nonscripted situations, we must become 'mindful' of our thought processes" (Gudykunst 1993: 41). In other words, one should be more reflective in the act of communication. This need to be reflective of the goal of any communication is critical in the legal context, where the "mindful" communicator is likely to be a better witness when reflecting on past events or incidents. Langer (1989: 69) expands and isolates three qualities of mindfulness:

(1) Creation of new categories;

(2) Openness to new information;

(3) Awareness of more than one perspective. 
Arguably, in the South African legal context, it is still the monolithic western paradigm or category that rules. There is little awareness or openness to any other perspective or category. Majeke (2002: 153) characterizes this as follows:

We all know that no legal system will ever succeed in establishing itself as a social system efficiently if it is not founded on the fundamental cultural rhythms of the majority of the population in its borders. Yet we continue to teach young indigenous Africans how to be good Roman, Dutch, and English law specialists. They are becoming foreigners in their own land.

This is pertinent to South African legal practitioners, and the extrapolation to African witnesses and non-legally trained participants is obvious.

\section{2. "Mindfulness": a comparative perspective}

Langer (1989) continues to point out that human beings naturally create categories in order to make sense of the world around them. "Any attempt to eliminate bias by attempting to eliminate perception of differences is doomed to failure" (Langer 1989: 154). From a comparative point of view, Eades (2005: 304-314) supports this stance when analysing the Australian court system in relation to Aborigines and the use of their dialect of English within the system. The cultural differences embedded in Aboriginal English, "the perception of differences", often contribute to miscommunication in the courts. She continues to point out that amongst Aborigines, direct questions are not important in information seeking, and that silence as an interaction is not an indication that communication has broken down (Eades 2005: 305).

These cultural underpinnings run contrary to standard Australian English culture and can be problematic in courts of law. She also points out that a lawyer's handbook has been published in order to create awareness and "mindfulness" (Eades 2005: 306). This "mindful" communication can be particularly complex when intercultural communication takes place, especially when the communicative event suffers from "cultural noise". Gibson (2002: 9) states that, 
[i]ntercultural communication takes place when the sender and the receiver are from different cultures. Communication can be very difficult if there is a big difference between the two cultures; if there is too much "cultural noise", it can break down completely.

On occasion "cultural noise" occurs between mother tongue speakers of isiXhosa themselves, where members of the bench, as well as the witnesses or accused, are isiXhosa mother tongue speaking, but the court medium of communication is English only, to the detriment of those isiXhosa speakers who do not understand English (Kaschula and Ralarala 2004: 257). The participants are then differentiated by what Ting-Toomey (1999: 6) refers to as "secondary dimensions of diversity". "Primary dimensions of diversity" would be those differences which are visible and unchangeable, such as race, whereas "secondary dimensions" involve aspects of socialisation, such as educational levels.

South African court rooms contain both primary and secondary dimensions of diversity, depending on the participants involved. Furthermore, Ting-Toomey (1999: 22-24) presents certain assumptions which will increase an individual's understanding of the intercultural communication process. These assumptions include the fact that intercultural communication always takes place in a context and within an embedded system. It does not happen in a vacuum: courts in South Africa represent a system where a western paradigm is de facto entrenched, adding wider responsibilities for translation structures, namely the need for language to be translated in context.

Carbaugh (1990: 151) recognizes that multilingual scenarios, such as the one in South Africa, with selected language bias towards English and Afrikaans, present a particular situation of intercultural contact which is fundamentally problematic. These problems are exacerbated in many South African law courts where cultural preferences for speaking do exist in these contexts, where some patterns are valued, and others are rendered somehow problematic. Arguably, it is these very "practical" problems as outlined by Carbaugh that are encapsulated in the term "practicable" in Chapter 1, Section 6 of the Constitution, which have undermined indigenous language usage in courts of law. This has threatened not only the equality to speak, 
but also to be heard in one's own language and context. In such a context, court proceedings should take place with the use of an effective and properly trained interpreting team.

\section{Language rights in South African law courts}

Language rights are enshrined in the South African Constitution of 1996 (Section 35 (3) (K)). However, this really amounts to nothing more than a variety of rights, which resemble privileges rather than fundamental rights in the real sense of the word (Kaschula and Ralarala 2004: 254-257). This allows leaders to negate the indigenous languages if they wish to do so, which further entrenches the hegemony of English, at least in the public domain. Furthermore, there are no procedures whatsoever when it comes to enforcing or securing these so-called language rights. This is suggested against the backdrop of South African law courts, as well as intercultural communication and what has been taking place in these courts, at least from a linguistic point of view. According to Moeketsi (1999: 127) "English and Afrikaans are the sole languages used to hear trials and to keep the court record." Judge Hlophe (2003: 2), the Judge President of the Cape High Court, stated that "it is clear that at present in the courts two languages continue to dominate." He continues to point out that there is a lack of "clear policy or commitment to the language issue."

However, this lack of commitment needs to be viewed as both a consequence of English hegemony, and the problems associated with the practicalities of administering a legal system in a complex multicultural environment with numerous legacy issues.

\section{Language, thought and context}

Inherent in concepts such as 'mindfulness', 'primary and secondary diversity', 'multilingualism' and 'intercultural communication', is the need to acknowledge the relationship between language and thought. It is against this backdrop that any suitable ICT solutions, if they exist, need to be developed.

Sociolinguistic theory recognizes a continuum between language and thought, "mould theories" and "cloak theories". Mould theories characterize language as "a mould in terms of which thought categories are cast" (Bruner et al. 1956: 11), while cloak theories offer the role 
of language as "a cloak conforming to the customary categories of thought of its speakers" (ibid). This distinction is further developed when addressing the "Sapir-Whorf hypothesis", which is associated with the two principles of linguistic determinism and linguistic relativity, where in the case of the former, our thought patterns are determined by our language, while in the case of the latter, speakers of different languages perceive and interface with the world differently (Chandler 1995: 89).

A rigorous treatment of the aspects of linguistic determinism and relativity is beyond the scope of this article. However, it is essential that the role of translation in the conveyance of message acts as a philosophical backdrop against which ICT solutions are explored and developed for any legal applications. Multilingual court rooms where a single language may dominate could present a situation where the standard Whorfian problems associated with translation from one language to another exist, further complicated by problems of context and perspectives. The latter could be as extreme as differences in the concept of justice as underpinned by what is deemed to be right or wrong. This could apply, for example, to perspectives on property ownership, community versus individual rights, rights of elders over others and so on.

If a less Whorfian perspective is adopted such as that presented by universalism, then it is acknowledged that "even totally different languages are not untranslatable" (Popper 1970: 56). Popper's use of "untranslatable" is ironic, as "most universalists do acknowledge that translation may on occasions involve a certain amount of circumlocution" (Chandler 1995: 92). However, this circumlocution may be central to the conveyance of context and the avoidance of "lost in translation" problems. This can be seen in examples of the cross-examination of a witness where the members of the bench are not conversant in the mother tongue of the witness, and where they ask a dichotomous question through an interpreter, who proceeds to engage in an extended dialogue with the witness, to return an answer of "no". In this case, much of the discussion was contextual and attempting to establish a suitable framework for posing a dichotomous question (Megaw 2008). ${ }^{1}$

A classic case of cultural misunderstanding which is portrayed in a South African film by Gavin Hood, entitled A Reasonable Man, develops this point. ${ }^{2}$ In a consultation room in prison, in which the lawyer offers to represent the accused (a boy) in a murder case, the lawyer and the interpreter converse as follows: 
Lawyer: $\quad$... tell him, he is charged with the murder of a baby.

Interpreter: Utholwa unetyala lokubulala umntwana, uyezwa? Indaba ukuthi wabulala umntwana. Wambulala! Wambulala! ("You have been found guilty of murdering a boy, do you understand? The point is you killed a baby. You killed him! You killed him!")

At another point in the courtroom, the Judge said: "Ask the accused whether he accepts his counselor's admission that he killed the baby", which was followed by the interaction below:

Interpreter: $\quad$ Uyakuvuma ukuthi ubulele ingane? ("Do you admit that you killed a baby?")

Accused: $\quad$ Ngibulele uTikoloshe! ("I killed a Tikoloshe!")

Interpreter: He says yes, My Lord.

Judge: He has said a good deal more than that, what exactly did he say?

Interpreter: My Lord, he says he killed a Tikoloshe.

Lawyer: $\quad$ An evil spirit, My Lord.

Beyond circumlocution, the notion of bias is characteristic of many courtroom crossexaminations, and this is in part displayed by the interpreter's intent to purposefully and consciously twist and turn the evidence being given by the accused, and thereby contribute to a perception of guilt, with the consequential impact on the application of justice. The notion of bias is crucial in the judicial context, which needs to be revisited as a frame of devising some form of an intervention towards achieving a system which is sensitive and responsive to the complex language and cultural situation in South African courts.

Mertz (1994: 436) shows that there has been extensive debate regarding language as an "instrument or reflection of social dynamics and language as an active participant in social construction". Within the legal context it is imperative to formalize this distinction, in terms of language used to convey information through semantic meaning, against language which "expresses and reflects social divisions and inequalities" (Mertz 1994: 436). This refers to the contextual meanings associated with any experience or conveyance of a perception of reality. The former is essential to supporting the application of the law, while the latter offers insights into the pitfalls that often plague the execution of justice. 
It is essential that the development of any ICT solutions is predicated on a philosophy of the role of language and its relationship to the development and communication of thought and context. An extreme Whorfian perspective will, by definition, preclude the development of suitable computer based solutions. However, given the status quo within the legal system, a coherent ICT structure that attempts to offer effective communication will offer in-roads towards the entrenchment of language rights, regardless of the language or dialect which is adopted and developed as a reference parameter.

Establishing a suitable neutral translation tool requires that practitioners be able and willing to recognise what can be "lost in translation", since in a legal paradigm, invariably, the witnesses' personal viewpoints are spurious to the application and achievement of a just outcome. However, individual context and thought may inform language and communication, and thus be relevant to the final outcomes through evaluation of the evidence. This dichotomy is best reflected by Eagleton in discussing the concept of reality in literature, as perceived by the structuralists and semioticians. He recognises that reality is not necessarily reflected by language "but produced by it"; that the way humans perceive the world is dependent on the sign-system (i.e., language) that they have at their command (Eagleton 1983: 55).

\section{Prosody and focus}

The scope for debate surrounding the role and relationship between language, thought, context and experience is extensive when attempting to develop a suitable ICT infrastructure to support an effective legal translation environment. However, it is less critical than the need to address issues associated with prosody, especially in the case of languages that are predominately oral and tonal.

Prosody addresses issues such as the conveyance of pitch and syllable length. These are essential to the communication context, and it is essential that the nuances associated with language are captured and delivered in an accessible manner to people who are required to use the information for the dispensing of justice. As with other aspects of this article, a detailed treatment of prosody is too wide. However, for the purpose of the debate, the article addresses issues of focus, using the pragmatic definition developed by Jackendoff (1972), where "focus" refers to that part of the clause that conveys the most salient information in the given context of 
the discourse. This simplification may offer a paradigm for the development of suitable algorithms or sequences of finite instructions which are often used for calculation and data processing. A list of well-defined instructions for completing a task will, when given an initial state, proceed through a well-defined series of successive states, eventually terminating in an end-state. This transition from one state to the next is not necessarily deterministic. Some probabilistic algorithms incorporate randomness (Ferreira 2007). However, as Ferreira recognizes, there are limitations to the use of algorithms. This is especially true in terms of the ability "to predict phenomena such as pauses or intonational breaks" as these "are problematic because they tend to conflate prosody and planning" (Ferreira 2007: 1151).

Given the legal context in South Africa, it is essential that any translation activities meet the demands of the focused intentions of the information contributor, and not the translator's or translation medium's interpretation. The aim for ICT developers will be "to deepen our understanding of whether and how the information-structural category of focus" acts to effect communication within the legal contexts in South Africa (Adoh et al. 2008: 1).

Many would argue that this is too wide to capture effectively in a software programme or to ensure that no errors occur. However, the wide swathe of focus and context elements can be tabulated where legal practitioners are presented with the possible meanings and then apply them to the relevant context. For example, the isiXhosa phrase "We saw the dawn through yesterday's eyes" carries a metaphorical focus and nuances, with little literal relevance. However, if the translator is not sensitive to the metaphor, much will be "lost in translation'; likewise, where focus is misinterpreted, the essence of evidence may be lost and result in a miscarriage of justice. Where witnessing "the dawn through yesterday's eyes" refers to not having slept the previous night, a literal interpretation lends little to the conveyance of context, which may be essential to a trial where the frame of mind of witnesses or their ability to recall events will have a central bearing on the execution of justice. A basic software programme could easily collect idiomatic and metaphorical phrases which would offer legal practitioners a better translation environment to act on behalf of mother tongue speakers and/or to exercise their judgments. 


\section{ICT translation support}

With the advent of new computer technologies and their increasing potential to solve communication challenges, there are possible solutions that could be harnessed to address the problems associated with intercultural communication as outlined above. The innate potential associated with hardware developments is clear. IBM introduced the first petacomputer in 2005 (a thousand trillion floating-point operations per second $\{$ FLOPS $\}$ ). It is likely that a 100 petaflops (equivalent to the human brain) will be developed by 2015 (Martin 2006: 122). While these machines will not replace humans, their potential for "real-time language translation" will become feasible. These breakthroughs will have an impact on intercultural communication, but the real question is: will their potential be significant in terms of the nuances, tone, intense language, vivid language, metaphoric language, equivocal language and prosody associated with languages? This represents the challenge associated with developing suitable solutions.

The complexity of prosody, focus and tone is well documented (Hirst and Di Cristo 1998). However, as Govender et al. (2006: 1) point out "the lack of widely-accepted descriptive standards for prosodic phenomena have meant that prosodic systems for most of the languages of the world have, at best, been described in impressionistic rule-based terms". This presents problems for the development of effective translation systems that are sympathetic to the nuances of languages that carry serious tonal characteristics. Govender at el. (2006: 1) continue as follows:

For languages of Southern Africa, the deficiencies in our modeling capabilities is acute when addressing languages which are excessively tonal viz: isiZulu and isiXhosa. Consequently, as is common for tonal languages, lexical tone can result in the same word carrying different meanings, while having the same phonetic characteristics. These present significant challenges when exploring the development of ICT based solutions for real-time language translations.

At a simplistic level the ICT process would operate as follows: 
1. The speaker is recorded on a voice recognition recording device which records and changes the language into text.

2. This text is applied to an analysis algorithm to determine where in the database each word should be stored.

3. The algorithm will determine the potential logical meaning(s) of the full sentence and create texts for each.

4. Once the logical output(s) has been determined, the PC will convert text-to-speech and this will be available to listeners in their mother tongue.

5. The process will synchronously develop to support mutual understanding.

Although this process is very straightforward in terms of the software functionality, the true challenges are associated with the construction of the databases that will support the process and the relevant algorithmic structures. These challenges are not insurmountable. However, there will have to be scope for systems errors to occur and thus the following questions arise: Will a system of this nature be more effective than the status quo? How do we capture the language tone and nuances effectively? Will the context of a case offer a fecund environment for a programme of this nature to be complementary to ensuring language rights? These questions are not exhaustive but they do offer a framework for addressing the challenges.

Govender et al. (2006) have started the exercise of building suitable tonal database sets for isiXhosa and isiZulu, and it is sets like these that will support the development of an effective translation tool. In order to capture the language nuances into their appropriate groups within the database, the algorithm would have to make use of two measurement guidelines. Govender et al. (2006: 2) attempt to address some of the database development issues by recording the initial and final value of the pitch in syllables in isiXhosa and isiZulu. By identification of an average value of each syllable in a word, the authors make initial in-roads into the establishment of some of the rules that will support the algorithms. By using these measurements it will be possible to categorize words in their appropriate utterance groups and to group these groups together to form a multi-tier database to convey the correct nuances to the listener. The challenge lies in developing effective classifiers to be used by the algorithm in order to match the indigenous language database with the English database in a manner that will produce a correct translation. Govender et al. (2006: 4) make use of a measurement system by creating classifiers through marking syllabic intonation as either high $(\mathrm{H})$ or low $(\mathrm{L})$. With 
this in mind it is feasible to theorize that using the pitch and amplitude, words could be further categorized in a level based classifier database structure; for example, "High" would have a value of 10, "Low" a value of 0 and a middle classifier a value of 5. This would make the translation process less complicated as the software would not be required to process extra calculations to match the group's intra-databases. Although the technical value of this is limited, it will make the software development process less costly.

Although algorithms for such translation have already been developed (Boersma 2001), the nuance differences between the isiXhosa language and the hegemonic languages used in today's law courts are yet to be represented through an effective identification algorithm. Thus using the above database structure the algorithm (the second algorithm in the system architecture) would have to match recorded utterances against a database of already identified nuances in all the languages used in the conversation.

Another challenge lies within each language's prosodic structures, where homonyms can prove problematic in the identification process when using an algorithm of this nature. This is illustrated by the example below, involving the words "lease" and "least":

The plaintiff (P) in a small claims court has rented a small plot of land to the defendant (D), on which a temporary abode has been built. A lease was agreed upon for a sum of R500 per month. The presiding officer (PO) is a first language speaker of English; all other parties are second language speakers. There is an interpreter present.

PO: Are both parties aware of the lease conditions?

P: $\quad$ Yes. (through interpreter)

D: Yes. (through interpreter)

PO: What is the issue at hand?

P: I signed a lease with the $\mathrm{D}$ and for six months she paid, but for the last six months she has paid only some of the monies.

PO: Is this true?

D: I did pay after six months but then went to see the P and said I would pay at least R300 per month which he said was acceptable.

PO: Is that correct? 
P: $\quad$ Yes but I thought she said she would pay the lease.

Thus, a third algorithm needs to be developed as an identifier of homonyms in each language set.

Horiguchi and Franz (1997: 97) discuss a translation architecture that could be used as a framework for indigenous to hegemonic language translation, as well as for an interpreting tool. This structure is built through the following process:

1. A speech analyzer utilizing algorithms (discussed earlier) files the data into the databases.

2. A morphological analyzer performs a check against the source language dictionary sets.

3. A shallow parser / syntactic analysis verifies the data according to the language rule set and dictionary databases.

4. An analogical transfer module uses a bilingual example database to translate and compile the output language data.

5. The target language generator performs a check against the output language rule set database and generates the translation.

6. Speech synthesis software produces the audio output.

Clearly, given the above as a guideline, it is feasible to theorize that through the development of working algorithms a solution for the use of ICT could be produced in order to reduce or eradicate intercultural language difficulties in South African law courts.

\section{Conclusion}

The problems of ensuring that entrenched language rights are made a reality in the South African courts of law present a number of challenges. The scope associated with the use of ICT for supporting translation between the participants is dependent on any intended programme's ability to capture nuances and/or tone in a manner that enhances the understanding of oral evidence on the part of non-indigenous language speakers. 
Due to the factors outlined above, it is unlikely in the foreseeable future that a perfect translation structure, making use of ICT, can be developed. However, the authors envisage a tool that will enhance the intercultural communication within courts of law. Limitations resulting from issues of prosody and context should not act as a barrier to this development. Effective structures will require a number of iterations and with suitable machine learning environments, extensive in-roads can be made to the realization of an effective and workable tool for promoting the entrenchment of language rights in South African courts of law. Extensive discussions need to ensue between linguistic practitioners and ICT specialists, as the need to consolidate effective translation structures in South African law courts is critical to the effective application of justice.

\section{*Acknowledgement}

We wish to acknowledge the following colleagues (Professors Ralph Webb, Felicia Roberts and Steven Wilson) from Purdue University for their insightful commentaries on an earlier version of this manuscript.

\section{Notes}

1. Megaw, R. E. 2008. Interview conducted by one of the authors. Megaw is a practising attorney of 45 years in the Pretoria Magistrate's Courts and a regular presiding officer for small claims courts.

2. A Gavin Hood film (a Moviworld production in association with African Media Entertainment and M-Net - Certificate: G/99/1498(V)), a portion of which has been cited to substantiate the authors' argument.

\section{References}

Adoh, E O., K. Hartmann and M. Zimmermann. 2008. Focus and grammar: The contribution of African languages. In E.O. Adoh, K. Hartmann and M. Zimmermann (eds). Trends in Linguistics. Studies and Monographs (TiLSM) 191. New York: Mouton de Gruyter. pp. 1-15.

Boersma, P. 2001. A system for doing phonetics by computer. Glot International 5: 341-345.

Bruner, J. S., J.J. Goodnow and G.A. Austin. 1956. A Study of Thinking. New York: Wiley. 
Carbaugh, R. (ed.). 1990. Crosscultural communication and intercultural contact. New Jersey: Lawrence Erlbaum and Associates Publishers.

Chandler, D. 1995. The Act of Writing: A Media Theory Approach. Aberystwyth: University of Wales.

Eades, D. 2005. Beyond difference and domination? Intercultural communication in legal contexts. In S.F. Kiesling and C.B. Paulston (eds). Intercultural discourse and communication. The essential readings. Oxford: Blackwell. pp. 304-316.

Eagleton, T. 1983. Literary Theory: An Introduction. Oxford: Basil Blackwell.

Ferreira, F. 2007. Prosody and performance in language production. Language and Cognitive Processes 22 (8): 1151-1177.

Gibson, R. 2002. Intercultural business communication. Oxford: Oxford University Press.

Govender, N., E. Barnard, V. Zimu, C. Kuun and M. Davel. 2006. Computational models of prosody for Nguni languages. Paper presented at ISCA Workshop on Multilingual Speech and Language Processing, 9-11 April, Stellenbosch, South Africa.

Gudykunst, W. 1993. Toward a theory of effective interpersonal and intergroup communication. In R. Wiseman and J. Koester (eds). Intercultural communication competence. London: Sage Publication. pp. 33-71.

Gudykunst, W. and C. Lee. 2003. Cross-cultural communication theories. In W. Gudykunst (ed.). Cross-cultural and intercultural communication. London: Sage Publications. pp. 7-34.

Gumperz, J.J. and D. Hymes. 1986. Directions in sociolinguistics. The ethnography of communication. New York/Oxford: Basil Blackwell Ltd.

Hirst, D. and A. Di Cristo. 1998. Intonation Systems. Cambridge: Cambridge University Press.

Hlophe, J. M. 2003. Receiving justice in your own language - the need for effective court interpreting in our multilingual society. Paper presented at CALSSA, at University of Cape Town, South Africa.

Horiguchi, K. and Franz, A. 1997. A problematic approach to analogical speech translation. Paper presented at Eurospeech '97 ( $5^{\text {th }}$ European conference on speech communication and technology) in Rhodes, Greece.

Jackendoff, R. 1972. Semantic Interpretation in Generative Grammar. Cambridge: MIT Press.

Kaschula, R.H. and M.K. Ralarala. 2004. Language rights, intercultural communication and the law in South Africa. South African Journal of African Languages 24 (4): 252-261. 
Kiesling, S. and C. Paulston (eds). 2005. Intercultural discourse and communication. The essential readings. Oxford: Oxford University Press.

Langer, E. 1989. Mindfulness. Reading, MA: Addison-Wesley.

Majeke, A. 2002. Towards a culture-based foundation for indigenous knowledge systems in the field of custom and law. In C.A. Odora Hoppers (ed.). Indigenous knowledge and the integration of knowledge systems. Towards a philosophy of articulation. Claremont: New Africa Books. pp. 141-157.

Martin, J. 2006. The meaning of the $21^{\text {st }}$ century - A vital blueprint for ensuring our future. London: Transworld Publishers.

Mertz, E. 1994. Legal Language: Pragmatics, Poetics and Social Power. Annual Review of Anthropology 23: 435-455.

Moeketsi, R. M. H. 1999. Discourse in a multilingual and multicultural courtroom. Pretoria: JL van Schaik Publishers.

Popper, K. 1970. Normal Science and its Dangers. In I. Lakatos and A. Musgrave (eds). Criticism and the Growth of Knowledge. Cambridge: Cambridge University Press. pp. $51-58$.

Saville-Troike, M. 1982. The ethnography of communication. An introduction. Oxford: Basil Blackwell.

Ting-Toomey, S. 1999. Communicating across cultures. New York, N.Y: Guilford Press.

Trudgill, P. 1983. Sociolinguistics. An introduction to language and society. Harmondsworth: Penguin Books. 